\title{
Effect of highly reflective building envelopes on outdoor environment temperature and indoor thermal loads using CFD and numerical analysis
}

\author{
Jihui Yuan ${ }^{1, *}$, Toshio Yamanaka ${ }^{1}$, Tomohiro Kobayashi ${ }^{1}$, Haruto Kitakaze ${ }^{1}$, and Kazuo Emura ${ }^{2}$ \\ ${ }^{1}$ Dept. of Architectural Eng., Graduate School of Eng., Osaka University, 2-1 Yamadaoka, Suita 565-0871, Osaka, Japan \\ ${ }^{2}$ Dept. of Housing and Environmental Design, Graduate School of Human Life Science, Osaka City University, 3-3-138 Sugimoto, \\ Sumiyoshi-ku, Osaka 558-8585, Osaka, Japan
}

\begin{abstract}
In recent years, the climate change (CC) and urban heat island (UHI) effects are becoming serious problems, affecting people's life and health, especially in hot summer. For large cities such as Tokyo and Osaka in Japan, the UHI effect is particularly intense. It is known that about $40 \%$ of urban anthropogenic heat comes from buildings in large cities. To reduce the anthropogenic heat of buildings is an important countermeasure to this problem. Strategies for UHI mitigation include urban ventilation, urban greening, green roof, highly reflective (HR) roads, and HR building envelopes, etc. Among these mitigation strategies, the research on HR building envelopes has been carried out globally. However, it is not clear that how the HR building envelopes affect the urban outdoor environment temperature and indoor thermal loads of urban buildings which is directly related to the selection of heating, ventilation and air conditioning (HVAC) system. Thus, this study aims to evaluate the effect of solar reflectivity of building envelopes varied from 0.1 to 0.9 , on the outdoor environment temperature and indoor thermal loads of buildings located on Osaka University Suita Campus, Japan, using Computational Fluid Dynamics (CFD) and numerical analysis.
\end{abstract}

\section{Background}

The urban heat island (UHI) effect is a well-documented climatic change phenomenon and is becoming very serious especially in the summer period due to the rapid increase of urban anthropogenic heat [1]. It was reported that the UHI intensity in hot climates may raise temperatures by $10^{\circ} \mathrm{C}$ [2], resulting in increased discomfort and higher pollution levels, while it has a serious impact on the cooling energy consumption of buildings $[3,4]$. In order to mitigate the UHI effect, many studies have focused on defining the relationship between rising temperatures and different urban elements [5-7]. A reviewed paper showed that the mitigation strategies such as; highly reflective (HR) and emissive light colored materials, cool colored materials, phase change materials (PCMs) and dynamic cool materials used for building roofs or facades, increasing urban albedo, green roofs, can significantly contribute to UHI mitigation and the improvement of urban environmental quality [8]. In addition, other studies have focused on the micro-scale showing the influence of urban design on the climate $[9,10]$.

Much research has shown that increasing the proportion of urban green covering or urban albedo can decrease the urban temperatures, reduce energy consumption of buildings and improve outdoor thermal comfort. Among the strategies of mitigating UHI effect,
HR coatings are being researched widely. A total of 93 pavement materials commonly used outdoors to increase the urban albedo for UHI mitigation were selected [11]. HR coating materials were applied to residential buildings in California and Florida, resulting in cooling energy savings of $10 \%-70 \%$ [12]. Smart paints applied to building facades for UHI mitigation and energy conservation were produced [13]. A total of five different black colorants produced in laboratory have been mixed with commercial paints and have been compared to the standard black colorant usually used for building paints. It showed that the surface temperature on the back of a painted support is lower as the total solar reflectance is higher, thus can be used for building energy conservation.

As known that the HR building envelopes will contribute to reducing cooling load of building during summer period for a city with hot summer such as Osaka, Japan [14]. Moreover, the influence of HR building envelopes on the outdoor environment temperature hasn't been discussed widely in Japan, this study aims to evaluate the effect of solar reflectivity of building envelopes on the outdoor environment air temperature and indoor thermal loads (including annual cooling load and annual heating load) with consideration of varying the solar reflectivity of building envelopes form 0.1 to 0.9 , using a Computational Fluid Dynamics (CFD) and numerical analysis.

* Corresponding author: en@arch.eng.osaka-u.ac.jp 


\section{Methodology and materials}

This paper used a CFD analysis to evaluate the influence of solar reflectivity of building envelopes on outdoor air temperature, and used a numerical analysis method, which is called "New HASP/ACLD- $\beta$ " commonly used in Japan for calculation of thermal loads [15].

\subsection{Simulation target}

This paper selected parts of buildings of Graduate school of Engineering of Osaka University Suita Campus $\left(34.8^{\circ} \mathrm{N}, 135.5^{\circ} \mathrm{E}\right)$ as simulation target (as shown in Fig.1). The area of selected buildings is approximately $140 \mathrm{~m} \times 160 \mathrm{~m}$, including S1 building, M2 M4 buildings, experiment buildings. Considering that the simulation analysis will receive the influence of the surrounding environment, the total simulation area is enlarged and set to $400 \mathrm{~m} \times 400 \mathrm{~m}$.

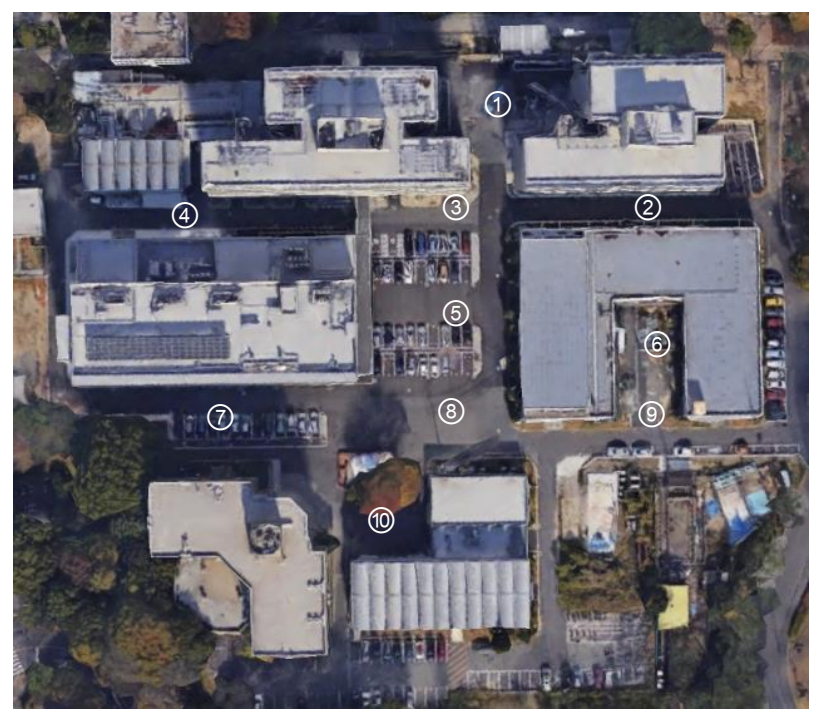

(1) (10) are measurement points at $Z=1.5 \mathrm{~m}$ )

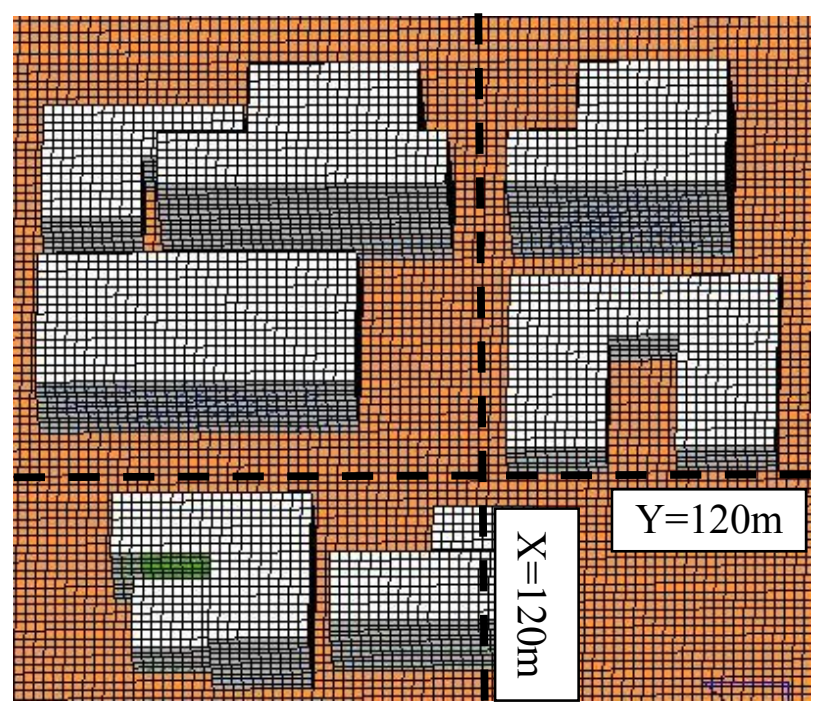

Fig. 1. Simulation target (buildings of Graduate school of Engineering of Osaka University Suita Campus).

\subsection{CFD analysis}

The STREAM V14 RC2, which is a CFD software often used in Japan [16], was chosen to evaluate the outdoor air temperature under different solar reflectivity of building envelopes.

The setting conditions of CFD analysis in this study are detailed in Table 1.

Table 1. Setting conditions of CFD analysis.

\begin{tabular}{|c|c|}
\hline Area of CFD analysis & $\mathrm{X}(400 \mathrm{~m}) \times \mathrm{Y}(400 \mathrm{~m}) \times \mathrm{Z}(200 \mathrm{~m})$ \\
\hline Flow type & Turbulent flow \\
\hline Turbulent model & $\begin{array}{l}\text { Standard k- } \varepsilon \text { model } \\
\text { (High Reynolds) }\end{array}$ \\
\hline Solar radiation & $\begin{array}{l}\text { July } 31^{\text {st }}, 2018,12: 00 \\
\text { (ASHRAE2013 Handbook) }\end{array}$ \\
\hline Boundary condition & $\begin{array}{l}X_{\min } \text { plane: Power law rule } \\
\text { boundary (Exponent reciprocal } \\
(\mathrm{n})=5 \text { ) } \\
\mathrm{X}_{\max } \text { plane: Natural outflow } \\
\text { boundary } \\
Y_{\min } \text { plane: Power law rule } \\
\text { boundary (Exponent reciprocal } \\
(\mathrm{n})=5 \text { ) } \\
Y_{\max } \text { plane: Natural outflow } \\
\text { boundary } \\
Z_{\min } \text { plane: Free slip } \\
Z_{\max } \text { plane: Free slip }\end{array}$ \\
\hline $\begin{array}{l}\text { Initial temperature of } \\
\text { inflow }\end{array}$ & $\begin{array}{l}28.9^{\circ} \mathrm{C} \text { (based on weather station } \\
\text { database of Osaka, Japan) }\end{array}$ \\
\hline $\begin{array}{l}\text { Building indoor } \\
\text { temperature }\end{array}$ & $24^{\circ} \mathrm{C}$ \\
\hline Wind speed & $\begin{array}{l}2.8 \mathrm{~m} / \mathrm{s} \text { at } 24 \mathrm{~m} \text { above the ground } \\
\text { (based on weather station } \\
\text { database of Osaka, Japan) }\end{array}$ \\
\hline Wind direction & Southwest \\
\hline Number of meshes & $1,304,240(144 \times 135 \times 61)$ \\
\hline Number of cycles & 5000 \\
\hline
\end{tabular}

The view of $X-Y$ plane, $Y-Z$ plane and $X-Z$ plane in the CFD simulation are shown in Fig.2a, Fig.2b and Fig.2c, respectively.
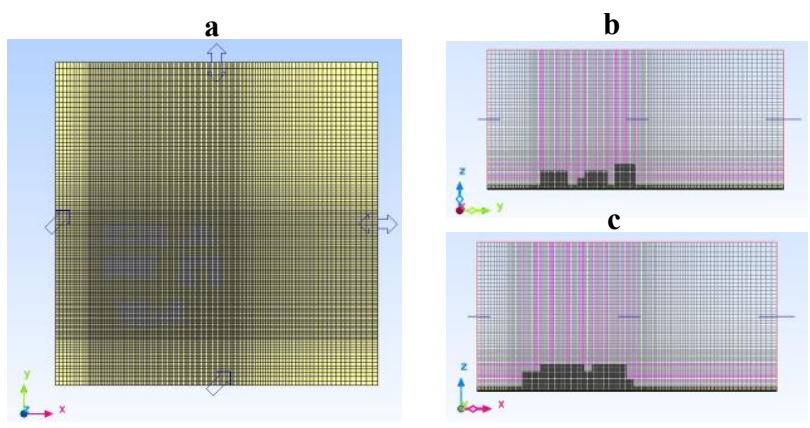

Fig. 2. View of $X-Y, Y-Z$ and $X-Z$ planes in the CFD simulation. 


\subsection{Calculation of thermal loads}

The numerical analysis method "New HASP/ACLD- $\beta$ " is used to calculate the thermal loads of simulation buildings. As EnergyPlus is used in U.S., "New HASP/ACLD- $\beta$ " is a simulation program often used to calculate the indoor temperature, humidity and thermal loads of buildings, which has been developed for the purpose of evaluating the energy consumption of airconditioning in buildings. Parameters in "New HASP/ACLD- $\beta$ " calculation program, such as the solar reflectivity of exterior walls, structure of building walls, operating condition of air conditioning, could be rewritten easily [17].

The condition of thermal load calculation is detailed in Table 2.

Table 2. Details of simulation building and conditions of building thermal load calculation.

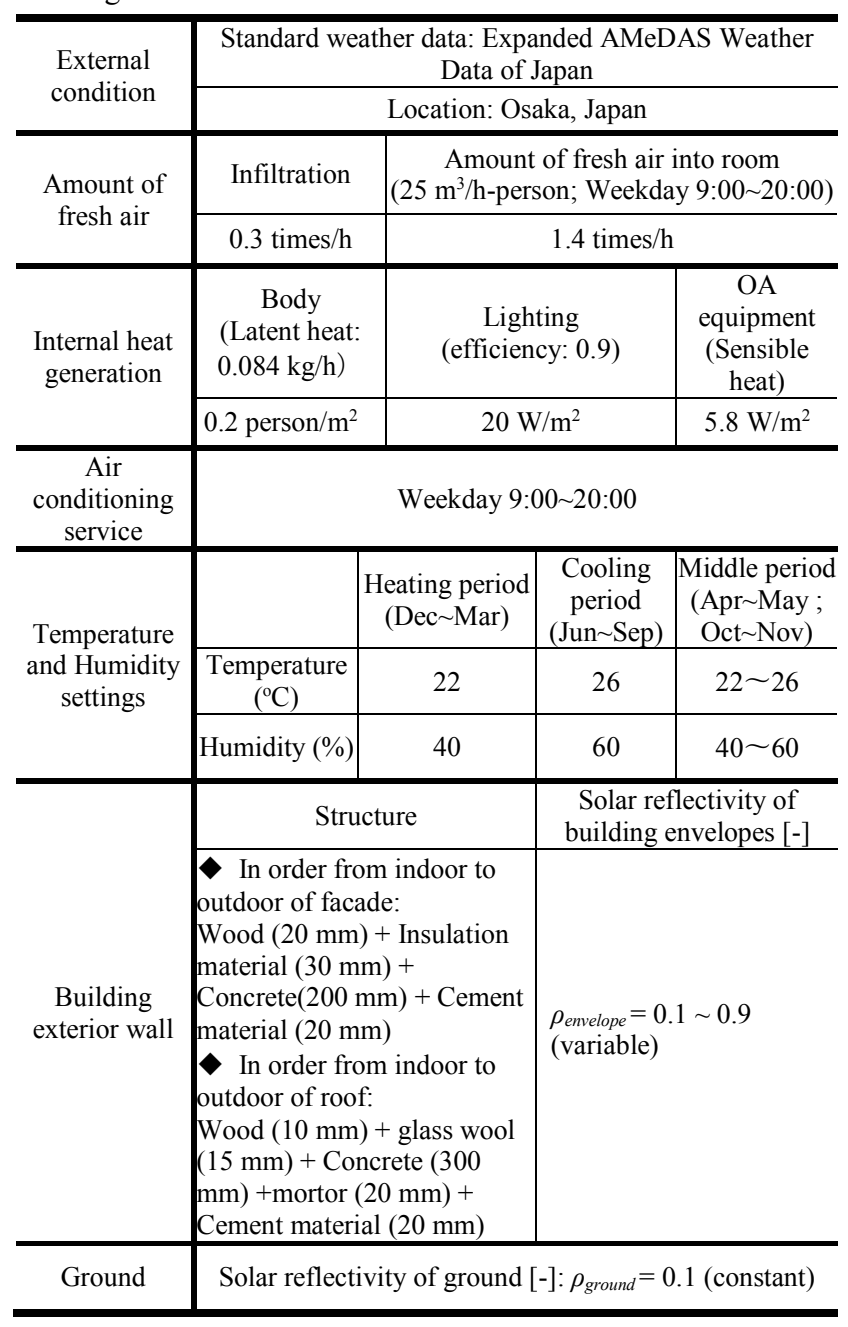

\section{Results and discussion}

In order to better know the distribution of outdoor air temperature under different scenarios with building envelope solar reflectivity of $0.1,0.3,0.5,0.7$ and 0.9 , images of outdoor air temperature distribution in cross sections (X-Y, Y-Z and X-Z planes) at 12:00 (July 31st 2018) are shown and compared in this study.
In addition, in order to evaluate the influence of solar reflectivity on the thermal loads of buildings, the annual heating load, annual cooling load and annual total thermal load under different solar reflectivity $(\rho)$ of $0.1 \sim 0.9$, are calculated and compared in this study.

\subsection{Results of outdoor air temperature}

The distribution of outdoor air temperature in cross section $X-Y$ plane at $Z=1.5 \mathrm{~m}$ height level under solar reflectivity of 0.1, 0.3. 0.5. 0.7 and 0.9 is shown in Fig.3.

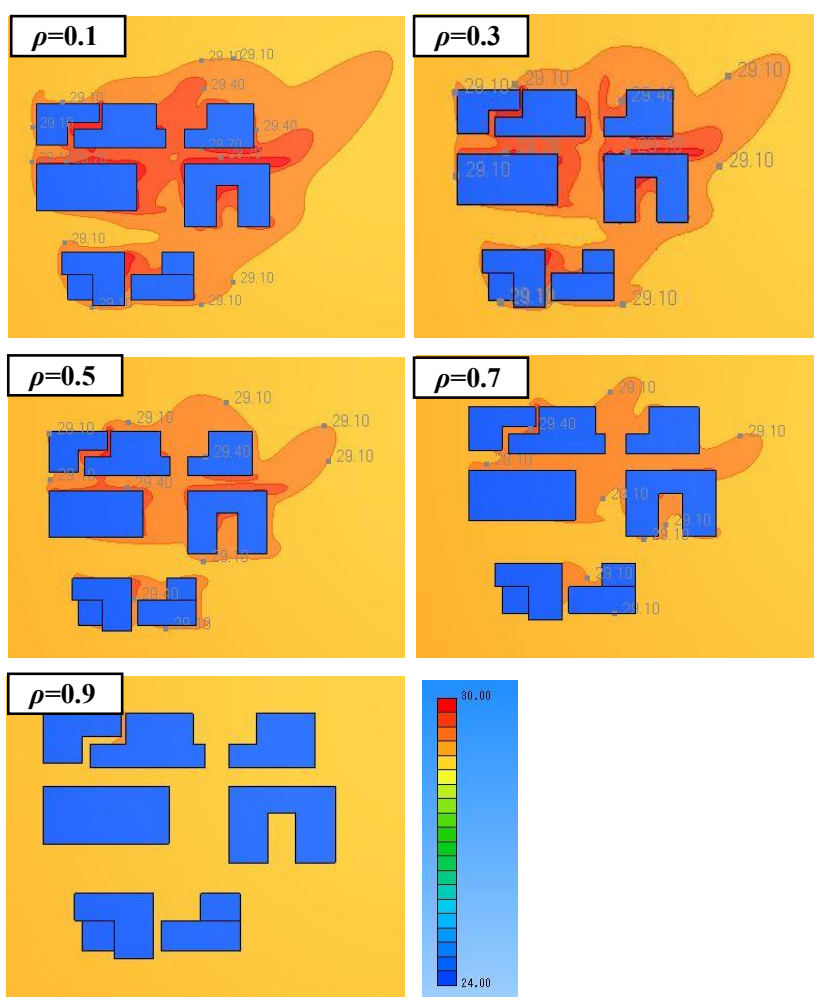

Fig. 3. Outdoor air temperature distribution of cross section $X$ $\mathrm{Y}$ section plane at $\mathrm{Z}=1.5 \mathrm{~m}$ height level under different solar reflectivity.

In addition, the change outdoor air temperature of 10 measurement points (as shown in Fig.1) at $Z=1.5 \mathrm{~m}$ height level under different solar reflectivity of $0.1,0.3$, 0.5, 0.7 and 0.9 are calculated and shown in Fig.4.

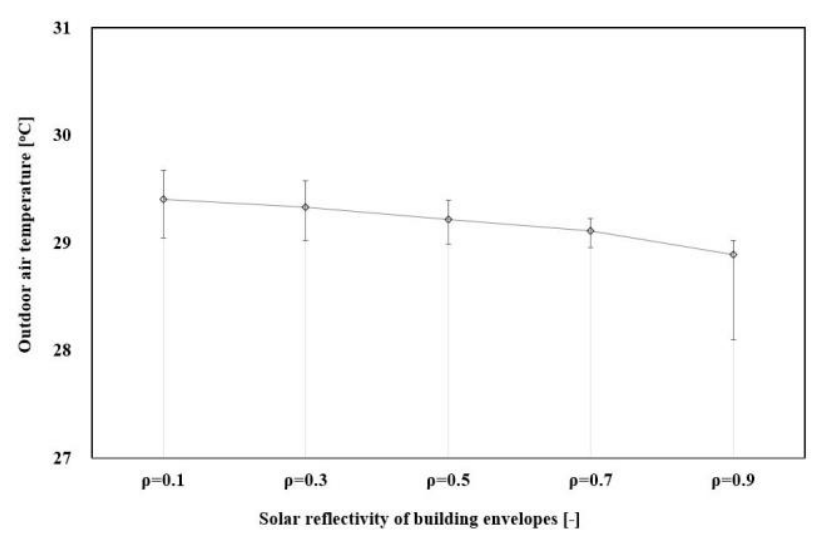

Fig. 4. Outdoor air temperature of 10 measurement points at $\mathrm{Z}=1.5 \mathrm{~m}$ height level under different solar reflectivity. 
The distribution of outdoor air temperature obtained from above results showed that the outdoor air temperature at an average human height level $(\mathrm{Z}=1.5 \mathrm{~m})$ is decreasing about $0.5^{\circ} \mathrm{C}$, while the solar reflectivity of building envelopes is varied from 0.1 to 0.9 .

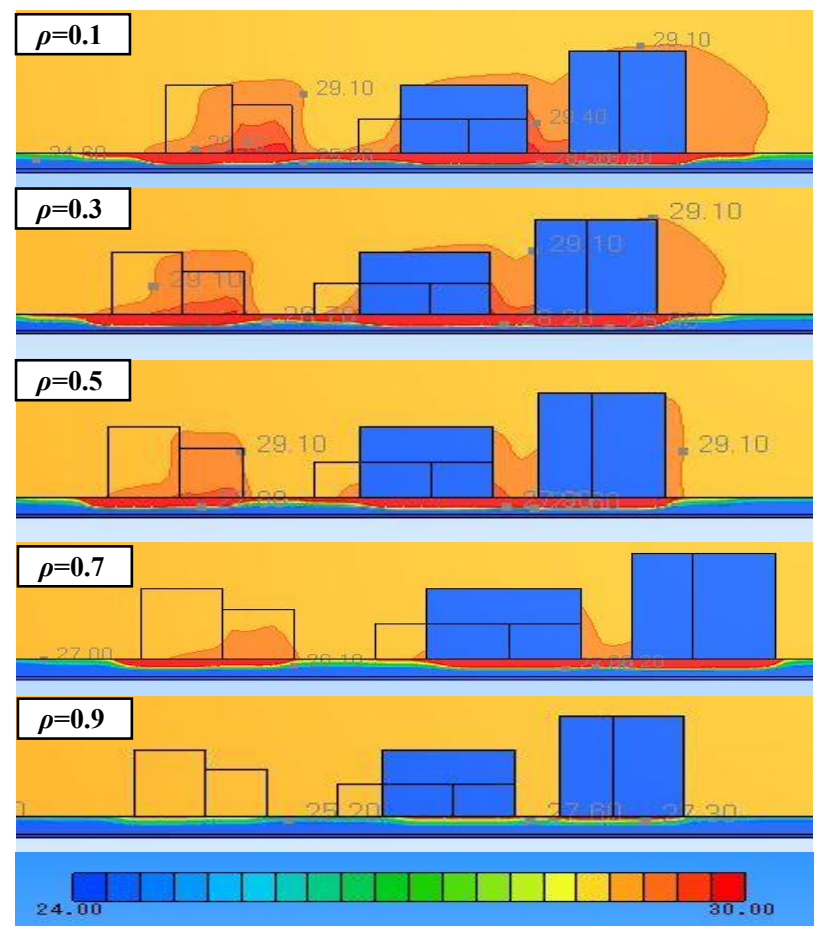

Fig. 5. Outdoor air temperature distribution of cross section $Y$ $Z$ section plane at $X=120 \mathrm{~m}$ height level under different solar reflectivity.
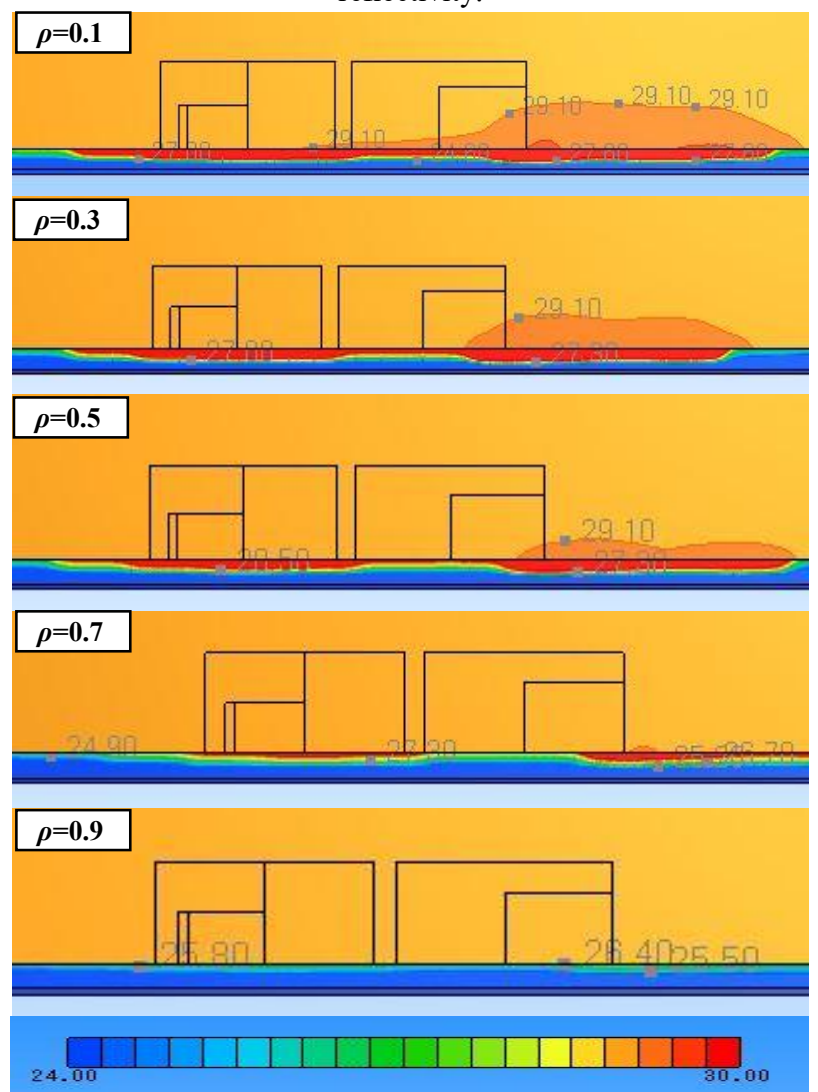

Fig. 6. Outdoor air temperature distribution of cross section $X$ $\mathrm{Z}$ section plane at $\mathrm{Y}=120 \mathrm{~m}$ height level under different solar reflectivity.
Moreover, the cross section $\mathrm{Y}-\mathrm{Z}$ (at $\mathrm{X}=120 \mathrm{~m}$ ) and $\mathrm{X}$ $\mathrm{Z}$ (at $\mathrm{Y}=120 \mathrm{~m}$ ) planes under different solar reflectivity of building envelopes are also obtained and shown in Fig.5 and Fig.6, respectively.

From Fig.5 and Fig.6, we can see that the distribution of outdoor air temperature for cross section $\mathrm{Y}-\mathrm{Z}$ and $\mathrm{X}-\mathrm{Z}$ planes are becoming uniform and the mean outdoor temperature are becoming lower, by varying the solar reflectivity of building envelopes from 0.1 to 0.9 .

We can conclude that the higher solar reflectivity of building envelopes, the lower outdoor air temperature. Thus, it is considered that HR building coatings will lower the outdoor air temperature during the summer period.

\subsection{Results of thermal loads}

The annual heating load, annual cooling load and annual total thermal load are calculated and shown in Figs.7, 8 and $\mathbf{9}$, respectively.

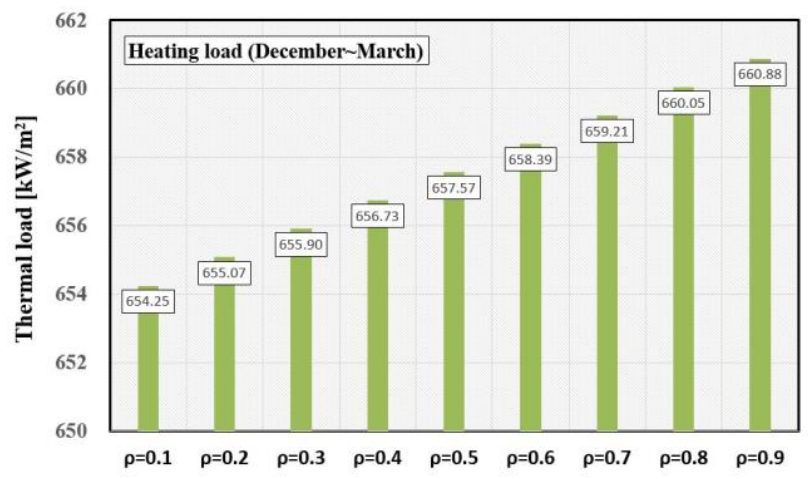

Fig. 7. Annual heating load under different solar reflectivity.

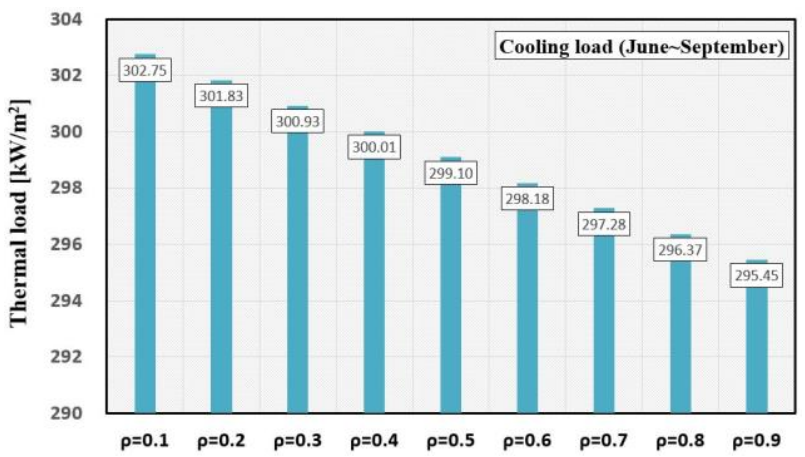

Fig. 8. Annual cooling load under different solar reflectivity.

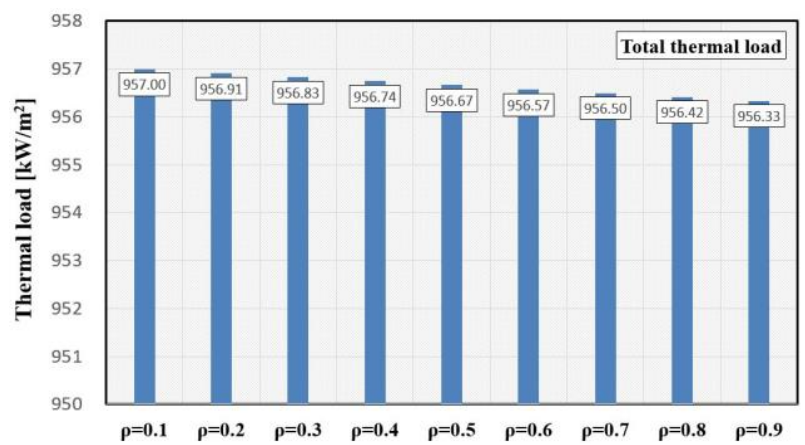

Fig. 9. Annual total thermal load under different solar reflectivity. 
Fig.7 shows that the annual heating load is increased by about $1 \%$ while varying the solar reflectivity of building envelopes from 0.1 to 0.9 .

Fig.8 shows that the annual cooling load is reduced by about $2.4 \%$ while varying the solar reflectivity of building envelopes from 0.1 to 0.9 .

Fig.9 shows that the annual total thermal load is reduced by about $0.01 \%$ while varying the solar reflectivity of building envelopes from 0.1 to 0.9 .

Thus, we can conclude that the HR building envelopes have a negative effect on the annual heating load, and positive effect on the annual cooling load and annual total thermal load.

\subsection{Discussion}

The CFD analysis of simulation buildings showed that the outdoor air temperature could be decreased by increasing the solar reflectivity of building envelopes. The numerical analysis of building thermal load by "New HASP/ACLD- $\beta$ " showed that the annual cooling load and annual total thermal load of buildings could be reduced, however the heating load would be slightly increased by increasing the solar reflectivity of building envelopes. Therefore, it is considered that the HR building envelopes may give an effective influence on the outdoor environment and lead to reducing the thermal load of buildings that is strongly related to energy savings.

The results have been obtained only from the simulation analysis, and maybe lack in field measurement. In addition, the CFD simulation analysis have been implemented at the time of highest solar elevation.

\section{Conclusions and future work}

This paper used the CFD and numerical analysis methods to evaluate the effect of solar reflectivity of building envelopes on the outdoor air temperature and thermal load of buildings. The knowledge are obtained and summarized as following,

- The outdoor air temperature can be lowered by about $0.5^{\circ} \mathrm{C}$, if the solar reflectivity of building envelopes are increased from 0.1 to 0.9 .

- The annual cooling load and annual total thermal load of buildings can be reduced by about $2.4 \%$ and about $0.01 \%$ respectively, by varying the solar reflectivity of building envelopes from 0.1 to 0.9 . However, the annual heating load of buildings will be increased by about $1 \%$ as a result.

For the future work, the research will be focused on comparison between CFD analysis and field measurement.

In addition, the future work is also aimed at implementing the research on the reflective directional characteristic of building envelope materials and evaluating the effect of reflective directional envelope materials (i.e., retro-reflective materials) on the outdoor environment, using CFD analysis method.

\section{References}

1. M. Santamouris. James and James Science Publishers: London, UK (2001)

2. I. Livada, M. Santamouris, K. Niachou, N. Papanikolaou, G. Mihalakakou. J. Theor. Appl. Climatol., 71, 219-230 (2002)

3. S. Hassid, M. Santamouris, N. Papanikolaou, A. Linardi, N. Klitsikas, C. Georgakis, D. Assimakopoulos. J. Energy Build., 32, 131-141 (2000)

4. J. Yuan, K. Emura, C. Farnham. Sustainability, 8, 514 (2016)

5. K.A. Gray, M.E. Finster. Department of Civil Engineering, Northwestern University, Evanston, IL (2000)

6. R. Giridharan, S. Laua, S. Ganesan, B. Givoni. Building and Environment, 42 (10), 3669-3684 (2006)

7. A. Ahmed, D. Ossen, E. Jamei, N. Manaf, I. Said, M. Ahmad. Theoretical and Applied Climatology, 115, 493-514 (2014)

8. M. Santamouris, A. Synnefa, T. Karlessi. Solar Energy, 85(12), 3085-3102 (2011)

9. M.J.N. Oliveira, H.J.P. Gonçalves, P.M.C. Ferrão. Building and Environment, 44(1), 177-187 (2009)

10. M. Idczak, D. Groleau, P. Mestayer, J. Rosant, J. Sini. Building and Environment, 45(5), 1262-1275 (2010)

11. L. Doulos, M. Santamouris, I. Livada. Solar Energy, 77(2), 231-249 (2004)

12. S. Bretz and H. Akbari. Energy and Buildings, 25(2), 159-167 (1997)

13. E.S. Cozza, M. Alloisio, A. Comite, G.Di. Tanna, S. Vicini. Solar Energy, 116, 108-116 (2015)

14. J. Yuan, K. Emura, C. Farnham. Sustainable Cities and Society, 32, 78-86 (2017)

15. The Society of Heating, Air-Conditioning and Sanitary Engineers of Japan (SHASEJ), Operation Manual of New HASP / ACLD- $\beta$ (2004) (in Japanese)

16. STREAM home page. Available online: https://www.cradle-cfd.com/ (accessed on 26 November 2018)

17. J. Yuan, C. Farnham, K. Emura, M.A. Alam. Building and Environment, 103, 228-237 (2016) 